\title{
Mechanical and Water Absorption Properties of Polymeric Compounds
}

\author{
Okonkwo Ebere Onyekachi, Kingsley Ogemdi Iwuozor* \\ Department of Pure and Industrial Chemistry, Nnamdi Azikiwe University Awka, Awka, Nigeria \\ Email address: \\ Realebista $a$ gmail.com (O. E. Onyekachi), Kingsleyiwuozor5@gmail.com (K. O. Iwuozor) \\ ${ }^{*}$ Corresponding author
}

To cite this article:

Okonkwo Ebere Onyekachi, Kingsley Ogemdi Iwuozor. Mechanical and Water Absorption Properties of Polymeric Compounds. American Journal of Mechanical and Materials Engineering. Vol. 3, No. 2, 2019, pp. 36-46. doi: 10.11648/j.ajmme.20190302.12

Received: November 20, 2018; Accepted: June 26, 2019; Published: July 10, 2019

\begin{abstract}
The use of polymers in reinforcement is a field that is gradually gaining momentum in the world of material science. The use of these polymers aids in reducing the menace of pollution attributed in the production of these materials. Till now, no work has been done on the use of polyacrylic resin in the reinforcement of material and that is what this research tries to throw more light on. This work is aimed at studying the effect of water absorption and the mechanical properties of polymeric Portland cement, Polymeric Barite and Polymeric Calcium carbonate, all locally blended in various ratios. The Mechanical and Water absorption properties of the mixture of Polyacrylic resin and Cement, Polyacrylic resin and Barite and Polyacylic resin and Calcium carbonate was analyzed. Eight different ratios of the Resin and Fillers were used in this work, viz; 90:10, 80:20, 70:30, 60:40, 50:50, 40:60, 30:70, 25:75, and 100\% of the Polymer. The Compressive, Tensile and Fleuxeral abilities of the wood samples were used to determine its Mechanical abilities. The experimental result obtained showed that as the resin was decreased, the strength as well as the Water absorption ability of the materials increased until it got to a peak from where it starts to decrease.
\end{abstract}

Keywords: Carbon Dioxide, Emission, Mechanical, Calcium Carbonate, Barite, Polyacrylic, Compressive

\section{Introduction}

The cement industry is no doubt one of the most thriving industries in any developed and developing countries but this industry has consistently contributed to carbon dioxide emissions in its production processes that aids in the depletion of the ozone layer [1]. During the production of cement, limestone in the form of calcium carbonate is decomposed to produce calcium oxide and carbon dioxide. This emission apart from producing poisonous calcium carbonate requires large volume of water too which could lead to water pollution [2]. Also, when concrete is being disposed, large amount of solid wastes are released into the environment. To checkmate these excesses, the need to reduce the amount of Portland cement needed led to the usage of solutions such as the supplementary cementitious materials like fly ash $[3,4]$.

Concrete is well recognized in the construction industry even though it is deficient in having low fleuxeral and tensile strength, it has very high compressive strength. This made the use of reinforcement to boost its shortcomings necessary. This reinforcement which may take the form of the addition of a good polymer is a research field that is currently thriving [5].

This research entails the use of polyacrylic resin as reinforcement on Portland cement, calcium carbonate and barite. The mechanical properties as well as its water absorption property were determined.

\section{Materials and Methods}

\subsection{Sample Collection}

The cement used was Ordinary Portland Cement (NIS 444, 2008) bought from a cement depot at Awka, The Polyacrylic resin; Calcium carbonate and Barite were bought from a drilling material shop at Boromi, Old road Nkpo Onitsha, Anambra state, Nigeria. 


\subsection{Materials}

The materials used for this research include:

i. Weighing balance

ii. Specimen mould

iii. Stirrer

iv. Aluminium foil

v. Polyacrylic resin

vi. Portland Cement (NIS 444, 2008)

vii. Calcium carbonate

viii. Barite

\subsection{Preparation of the Mould}

Wooden moulds of $150 \mathrm{~mm} \times 225 \mathrm{~mm} \times 450 \mathrm{~mm}$ was made, the moulds were made of wood and a tape used to cover the base, The moulds were also designed so that they can be removed easily. This was done so that the specimens conformed to the standards required for compression, flexural and tensile strength testing.

\subsection{Preparation of the Blends}

Different masses of the blends and filler were weighed with the aid of a weighing balance on an Aluminum foil. Nine blends each were produced for the mixture of the Resin and the three fillers namely: Cement, Barite and Calcium carbonate to give a total of Twenty-seven different blends. The blends were present in the ratio 100:0, 90:10, 80:20, $70: 30,60: 40,50: 50,40: 60,30: 70$, and $25: 75$. The mass of the various blends is given below.

\subsubsection{The Ratios and Amount of the Polymer and the Materials}

\section{(i). Poly Acrylic Resins (Resin) and Cement (Filler)}

Table $1.100 \%$ resin to $0 \%$ cement.

\begin{tabular}{ll}
\hline Ingredients & Weight in $\mathbf{~ k g}$ \\
\hline Poly acrylic resins & 0.2012 \\
Cement & 0 \\
\hline
\end{tabular}

Table $2.90 \%$ resin to $10 \%$ cement.

\begin{tabular}{ll}
\hline Ingredients & Weight in $\mathbf{~ k g}$ \\
\hline Poly acrylic resin & 0.18108 \\
Cement & 0.02307 \\
\hline
\end{tabular}

Table $3.80 \%$ resin to $20 \%$ cement.

\begin{tabular}{ll}
\hline Ingredients & Weight in $\mathbf{~ k g}$ \\
\hline Poly acrylic resin & 0.16096 \\
cement & 0.04615 \\
\hline
\end{tabular}

Table $4.70 \%$ resin to $30 \%$ cement.

\begin{tabular}{ll}
\hline Ingredients & Weight in kg \\
\hline Poly acrylic resin & 0.14084 \\
cement & 0.06922 \\
\hline
\end{tabular}

Table 5. $60 \%$ resin to $40 \%$ cement.

\begin{tabular}{ll}
\hline Ingredients & Weight in kg \\
\hline Poly acrylic resin & 0.12072 \\
cement & 0.09229 \\
\hline
\end{tabular}

Table 6. $50 \%$ resin to $50 \%$ cement.

\begin{tabular}{ll}
\hline Ingredients & Weight in $\mathbf{~ k g}$ \\
\hline Poly acrylic resin & 0.01006 \\
cement & 0.21596 \\
\hline
\end{tabular}

Table $7.40 \%$ resin to $60 \%$ cement.

\begin{tabular}{ll}
\hline Ingredients & Weight in kg \\
\hline Poly acrylic resin & 0.08048 \\
cement & 0.13844 \\
\hline
\end{tabular}

Table $8.30 \%$ resin to $70 \%$ cement.

\begin{tabular}{ll}
\hline Ingredients & Weight in kg \\
\hline Poly acrylic resin & 0.06036 \\
cement & 0.16151 \\
\hline
\end{tabular}

Table $9.25 \%$ resin to $75 \%$ cement.

\begin{tabular}{ll}
\hline Ingredients & Weight in kg \\
\hline Poly acrylic resin & 0.0503 \\
cement & 0.173025 \\
\hline
\end{tabular}

\section{(ii). Poly Acrylic Resins (Resin) and Barite (Filler)}

Table $10.100 \%$ resin to $0 \%$ barite.

\begin{tabular}{ll}
\hline Ingredients & Weight in kg \\
\hline Poly acrylic resins & 0.2012 \\
barite & 0 \\
\hline
\end{tabular}

Table $11.90 \%$ resin to $10 \%$ barite.

\begin{tabular}{ll}
\hline Ingredients & Weight in $\mathbf{~ k g}$ \\
\hline Poly acrylic resin & 0.18108 \\
barite & 0.0241 \\
\hline
\end{tabular}

Table $12.80 \%$ resin to $20 \%$ barite.

\begin{tabular}{ll}
\hline Ingredients & Weight in kg \\
\hline Poly acrylic resin & 0.16096 \\
barite & 0.20916 \\
\hline
\end{tabular}

Table $13.70 \%$ resin to $30 \%$ barite.

\begin{tabular}{ll}
\hline Ingredients & Weight in $\mathbf{~ k g}$ \\
\hline Poly acrylic resin & 0.14084 \\
barite & 0.07240 \\
\hline
\end{tabular}

Table $14.60 \%$ resin to $40 \%$ barite.

\begin{tabular}{ll}
\hline Ingredients & Weight in kg \\
\hline Poly acrylic resin & 0.12072 \\
barite & 0.09640 \\
\hline
\end{tabular}

Table $15.50 \%$ resin to $50 \%$ barite.

\begin{tabular}{ll}
\hline Ingredients & Weight in kg \\
\hline Poly acrylic resin & 0.1006 \\
barite & 0.1206 \\
\hline
\end{tabular}


Table $16.40 \%$ resin to $60 \%$ barite.

\begin{tabular}{ll}
\hline Ingredients & Weight in kg \\
\hline Poly acrylic resin & 0.08048 \\
barite & 0.1446 \\
\hline
\end{tabular}

Table $17.30 \%$ resin to $70 \%$ barite.

\begin{tabular}{ll}
\hline Ingredients & Weight in $\mathbf{~ k g}$ \\
\hline Poly acrylic resin & 0.06036 \\
barite & 0.16870 \\
\hline
\end{tabular}

Table $18.25 \%$ resin to $75 \%$ barite.

\begin{tabular}{ll}
\hline Ingredients & Weight in $\mathbf{k g}$ \\
\hline Poly acrylic resin & 0.05030 \\
barite & 0.18075 \\
\hline
\end{tabular}

\section{(iii). Poly Acrylic Resins (Resin) and Calcium Carbonate (Filler)}

Table $19.100 \%$ resin to $0 \%$ calcium carbonate

\begin{tabular}{ll}
\hline Ingredients & Weight in $\mathbf{k g}$ \\
\hline Poly acrylic resins & 0.2012 \\
calcium carbonate & 0 \\
\hline
\end{tabular}

Table 20. $90 \%$ resin to $10 \%$ calcium carbonate.

\begin{tabular}{ll}
\hline Ingredients & Weight in $\mathbf{k g}$ \\
\hline Poly acrylic resin & 0.18108 \\
calcium carbonate & 0.02180 \\
\hline
\end{tabular}

Table $21.80 \%$ resin to $20 \%$ calcium carbonate.

\begin{tabular}{ll}
\hline Ingredients & Weight in $\mathbf{~ k g}$ \\
\hline Poly acrylic resin & 0.16096 \\
calcium carbonate & 0.04360 \\
\hline
\end{tabular}

Table 22. $70 \%$ resin to $30 \%$ calcium carbonate.

\begin{tabular}{ll}
\hline Ingredients & Weight in kg \\
\hline Poly acrylic resin & 0.14084 \\
calcium carbonate & 0.06550 \\
\hline
\end{tabular}

Table $23.60 \%$ resin to $40 \%$ calcium carbonate

\begin{tabular}{ll}
\hline Ingredients & Weight in kg \\
\hline Poly acrylic resin & 0.12072 \\
calcium carbonate & 0.08730 \\
\hline
\end{tabular}

Table $24.50 \%$ resin to $50 \%$ calcium carbonate.

\begin{tabular}{ll}
\hline Ingredients & Weight in $\mathbf{~ k g}$ \\
\hline Poly acrylic resin & 0.1006 \\
calcium carbonate & 0.1090 \\
\hline
\end{tabular}

Table $25.40 \%$ resin to $60 \%$ calcium carbonate

\begin{tabular}{ll}
\hline Ingredients & Weight in $\mathbf{~ k g}$ \\
\hline Poly acrylic resin & 0.08048 \\
calcium carbonate & 0.13080 \\
\hline
\end{tabular}

Table 26. $30 \%$ resin to $70 \%$ calcium carbonate.

\begin{tabular}{ll}
\hline Ingredients & Weight in $\mathbf{~ k g}$ \\
\hline Poly acrylic resin & 0.06036 \\
calcium carbonate & 0.15262 \\
\hline
\end{tabular}

Table $27.25 \%$ resin to $75 \%$ calcium carbonate.

\begin{tabular}{ll}
\hline Ingredients & Weight in kg \\
\hline Poly acrylic resin & 0.0503 \\
calcium carbonate & 0.1635 \\
\hline
\end{tabular}

\subsubsection{The Weight of the Resins to the Fillers After Mixing}

Table 28. Resin and Cement.

\begin{tabular}{ll}
\hline Ratio of the mixture of resin and cement & Weight after mixing in $\mathbf{~ g}$ \\
\hline 100:0 (standard: only resin) & 0.2012 \\
90:10 & 0.20415 \\
$80: 20$ & 0.20711 \\
$70: 30$ & 0.21006 \\
$60: 40$ & 0.21301 \\
$50: 50$ & 0.21596 \\
$40: 60$ & 0.21892 \\
$30: 70$ & 0.22187 \\
$25: 75$ & 0.22332 \\
\hline
\end{tabular}

Table 29. Resin and Barite.

\begin{tabular}{ll}
\hline Ratio of mixture of resin and barite & Weight after mixing in $\mathbf{~ k g}$ \\
\hline 100:0 (standard) & 0.2012 \\
$90: 10$ & 0.20518 \\
$80: 20$ & 0.20916 \\
$70: 30$ & 0.21324 \\
$60: 40$ & 0.21712 \\
$50: 50$ & 0.2212 \\
$40: 60$ & 0.22508 \\
$30: 70$ & 0.22906 \\
$25: 75$ & 0.23105 \\
\hline
\end{tabular}

Table 30. Resin and Calcium carbonate.

\begin{tabular}{ll}
\hline $\begin{array}{l}\text { Ratio of mixture of resin and calcium } \\
\text { carbonate }\end{array}$ & Weight after mixing in $\mathbf{~ g}$ \\
\hline 100:0 (standard) & 0.2012 \\
90:10 & 0.20216 \\
$80: 20$ & 0.20456 \\
$70: 30$ & 0.20634 \\
$60: 40$ & 0.20802 \\
$50: 50$ & 0.20960 \\
$40: 60$ & 0.21128 \\
$30: 70$ & 0.21298 \\
$25: 75$ & 0.21380 \\
\hline
\end{tabular}

\subsection{Curing}

Water curing method was adopted for this research. The moulds were left where they were moulded and sprinkling method of curing was adopted. Sprinkling was done twice daily until curing age was reached.

Curing the cubes was done to increase it's level of hydration and improve the strength of the cubes. Curing took place from the second day of production till sixty (60) days later.

\subsection{Experimental Procedures}

\subsubsection{Test for Water Absorption of the Samples}

Water absorption is defined as the quantity of water 
withdrawn by a particular sample at specific conditions. For the water absorption test, the specimen were exposed under the atmosphere or dried with an oven for a specified time and temperature. Immediately upon cooling (if you use oven) the specimens were weighed. The material was submerged in water for a timeframe of two days. After two days, the sample was taken out from the water, dried and reweighed.

Data:

Water absorption is expressed as the percentage increase in the weight of the sample;

Percent Water Absorption $=[($ Weight of wet sample - weight of dried sample)/ weight of dried sample] x 100\%.

\subsubsection{Mechanical Analysis}

The cured moulds were then tested for their compressive, tensile and fleuxeral strength using the procedures below;

Compressive Strength Test

The compressive strengths of the blocks were carried out with the aid of a universal testing machine as indicated in BS
1881.

The surface dried blocks were weighed after which they were placed centrally on the testing machine. The knob of the machine was adjusted to firmly hold the block. Load was applied and the failure load determined for the blocks of each replacement.

The average crushing load for each was recorded and the compressive strength was calculated for each replacement relationship:

$$
\text { Compressive strength }=\frac{\text { Mean failure load }(\mathrm{N})}{\text { Cross sectional area }\left(\mathrm{mm}^{2}\right)}
$$

Splitting Tensile Test

This test will be finding the ultimate load for splitting tensile strength. This was be done using the same sized samples as the compression testing, however the force was applied to the longitudinal edge of the specimen rather than the top of the specimen.

\section{Results}

\subsection{Water Absorption}

Table 31. The water absorption of polymeric cement.

\begin{tabular}{llll}
\hline Ratio of mixture of resin and cement & Weight before curing in kg & Weight after curing in kg & Water Absorption (\%) \\
\hline $100: 0$ (standard) & 0.2012 & - & - \\
$90: 10$ & 0.20415 & 0.20423 & 0.04 \\
$80: 20$ & 0.20711 & 0.20722 & 0.05 \\
$70: 30$ & 0.21006 & 0.21312 & 0.05 \\
$60: 40$ & 0.21301 & 0.21607 & 0.05 \\
$50: 50$ & 0.21596 & 0.21904 & 0.05 \\
$40: 60$ & 0.21892 & 0.22198 & 0.05 \\
$30: 70$ & 0.22187 & 0.22343 & 0.05 \\
$25: 75$ & 0.22333 & & 0.04 \\
\hline
\end{tabular}

Table 32. The water absorption of polymeric Barite.

\begin{tabular}{llll}
\hline Ratio of mixture of resin and barite & Weight before curing in kg & Weight after curing in kg & Water Absorption (\%) \\
\hline $100: 0$ (standard) & 0.2012 & - & - \\
$90: 10$ & 0.20518 & 0.20523 & 0.02 \\
$80: 20$ & 0.20916 & 0.20923 & 0.03 \\
$70: 30$ & 0.21324 & 0.21330 & 0.03 \\
$60: 40$ & 0.21712 & 0.22127 & 0.04 \\
$50: 50$ & 0.22120 & 0.22513 & 0.03 \\
$40: 60$ & 0.22508 & 0.22915 & 0.02 \\
$30: 70$ & 0.22906 & 0.23111 & 0.04 \\
$25: 75$ & 0.23105 & & 0.03 \\
\hline
\end{tabular}

Table 33. The water absorption of polymeric Calcium carbonate.

\begin{tabular}{llll}
\hline Ratio of mixture of resin and cement & Weight before curing in kg & Weight after curing in kg & Water Absorption (\%) \\
\hline $100: 0$ (standard) & 0.2012 & - & - \\
$90: 10$ & 0.20216 & 0.20219 & 0.01 \\
$80: 20$ & 0.20456 & 0.20459 & 0.02 \\
$70: 30$ & 0.20634 & 0.20837 & 0.02 \\
$60: 40$ & 0.20802 & 0.20966 & 0.02 \\
$50: 50$ & 0.20960 & 0.21131 & 0.03 \\
$40: 60$ & 0.21128 & 0.21301 & 0.01 \\
$30: 70$ & 0.21298 & 0.21383 & 0.01 \\
$25: 75$ & 0.21380 & \\
\hline
\end{tabular}




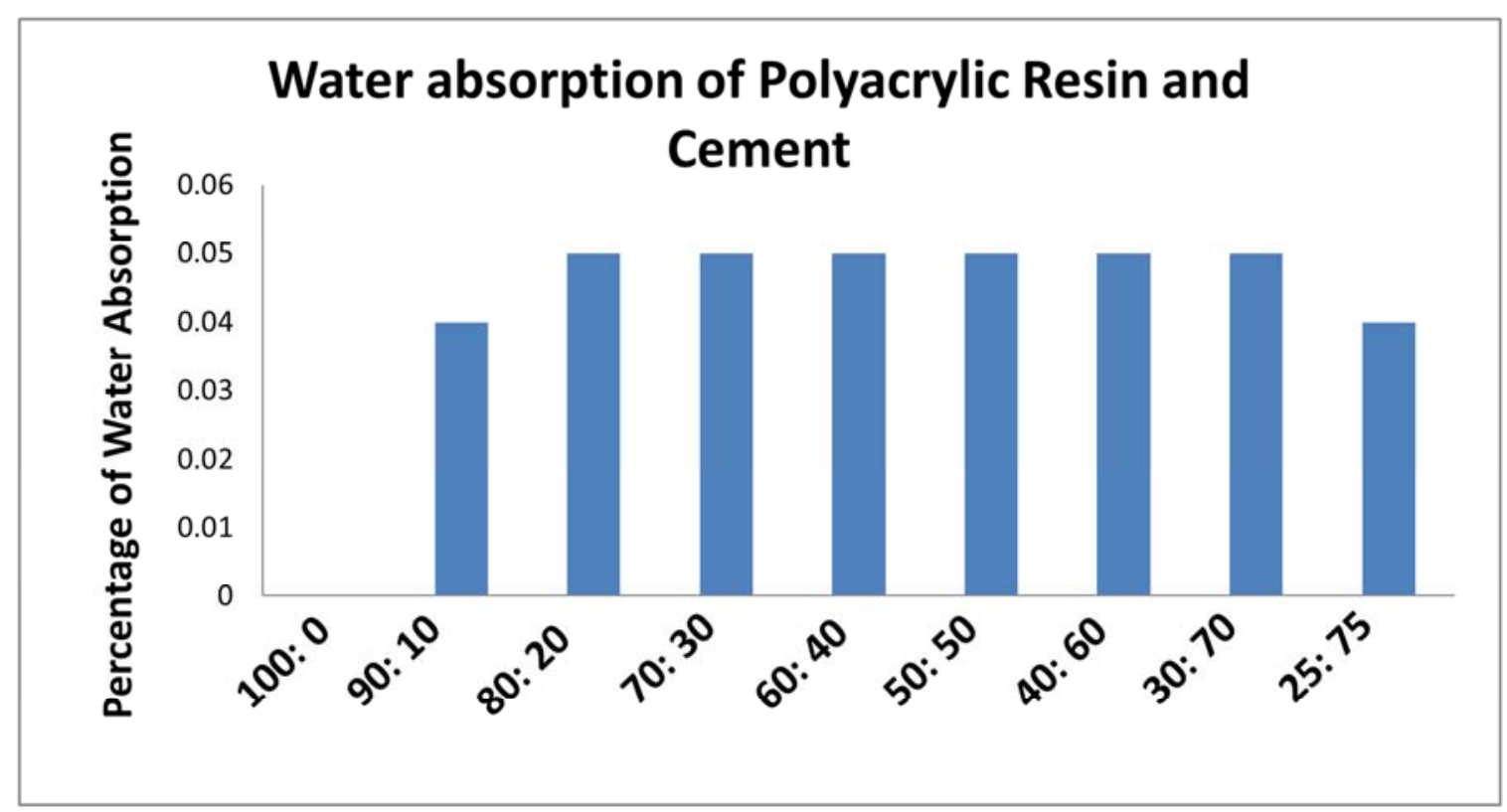

Figure 1. The Water absorption of Polymeric Cement.

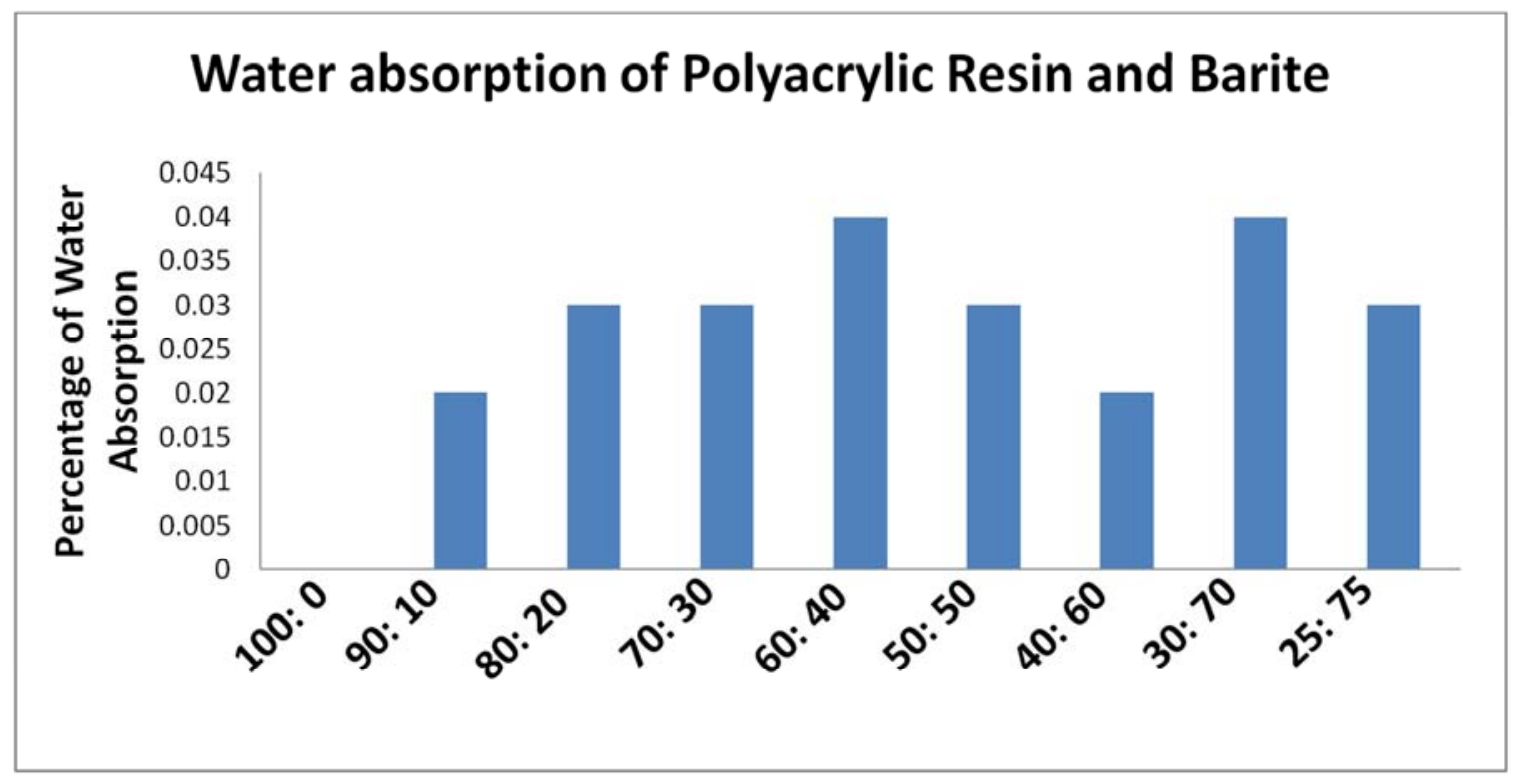

Figure 2. The Water absorption of Polymeric Barite.

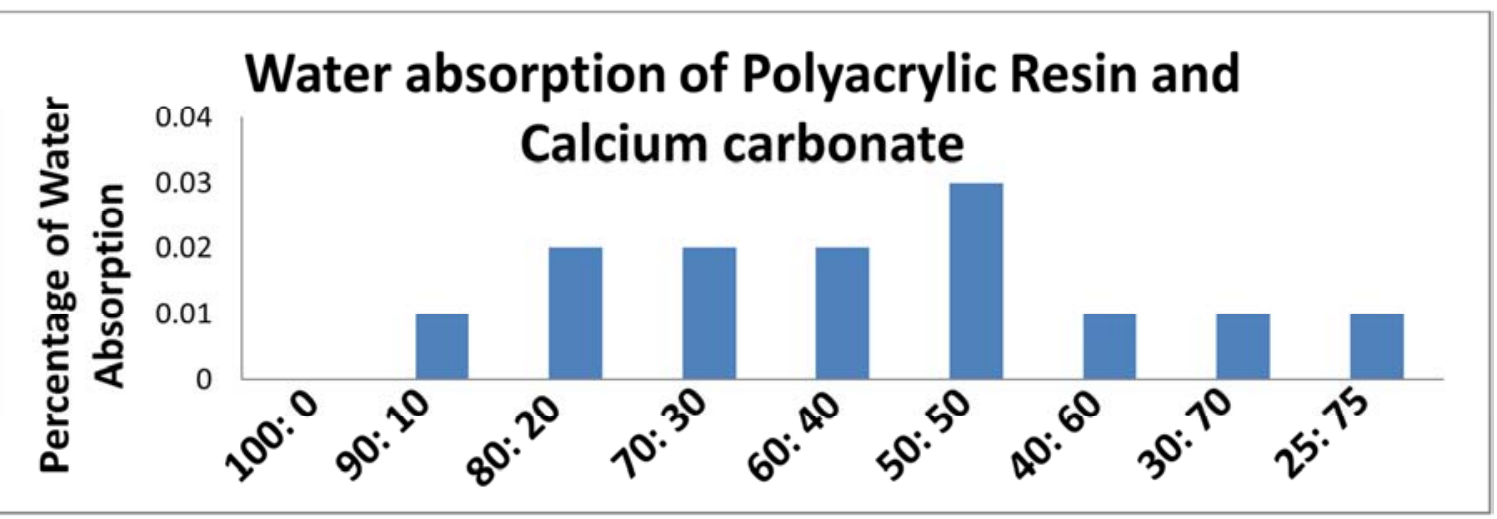

Figure 3. The Water absorption of Polymeric Calcium carbonate. 


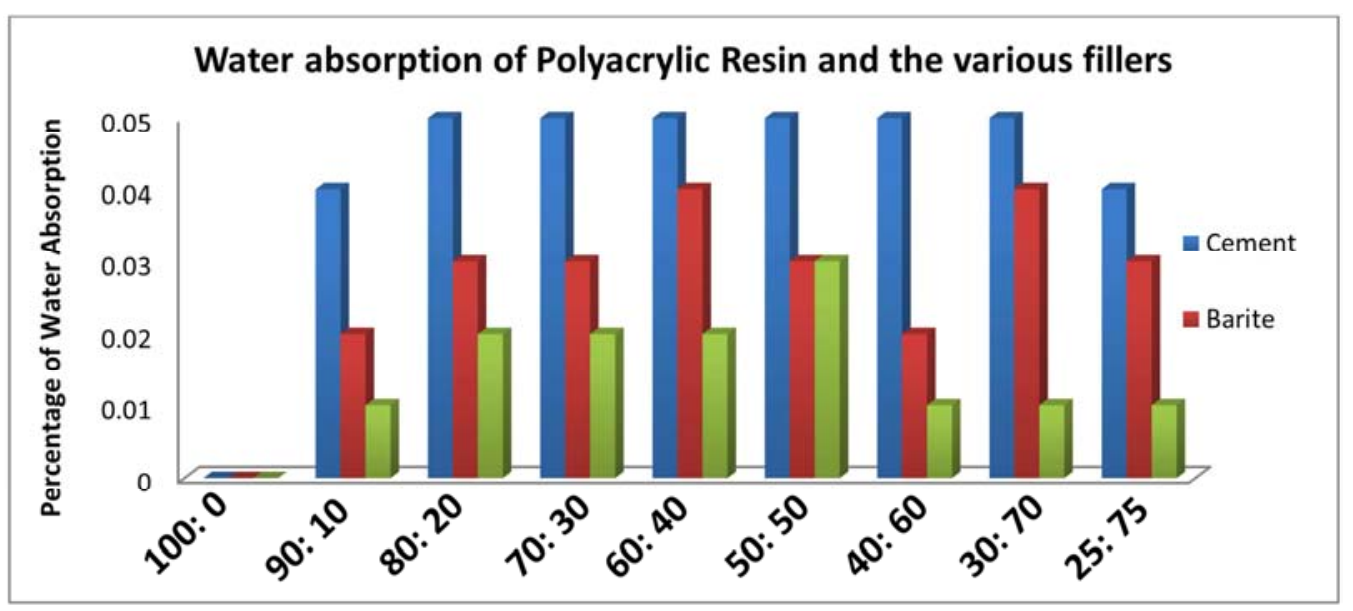

Figure 4. The Water absorption of Polyacrylic resin and the fillers.

3.2. Mechanical Properties of Polymeric Cement

Table 34. For the mixture of Resin and Cement.

\begin{tabular}{llll}
\hline Ratio of mixture of resin and cement & Compressive Strength (MPa) & Tensile Strength (MPa) & Fleuxeral Strength (MPa) \\
\hline 100:0 (standard) & - & - & - \\
$90: 10$ & 38.675 & 10.317 & 14.53 \\
$80: 20$ & 52.731 & 11.429 & 12.13 \\
$70: 30$ & 79.862 & 13.364 & 15.90 \\
$60: 40$ & 98.784 & 15.698 & 28.31 \\
$50: 50$ & 91.625 & 16.932 & 26.20 \\
$40: 60$ & 89.555 & 17.004 & 23.74 \\
$30: 70$ & 88.231 & 16.855 & 22.86 \\
$25: 75$ & 81.461 & 14.321 & 18.70 \\
\hline
\end{tabular}

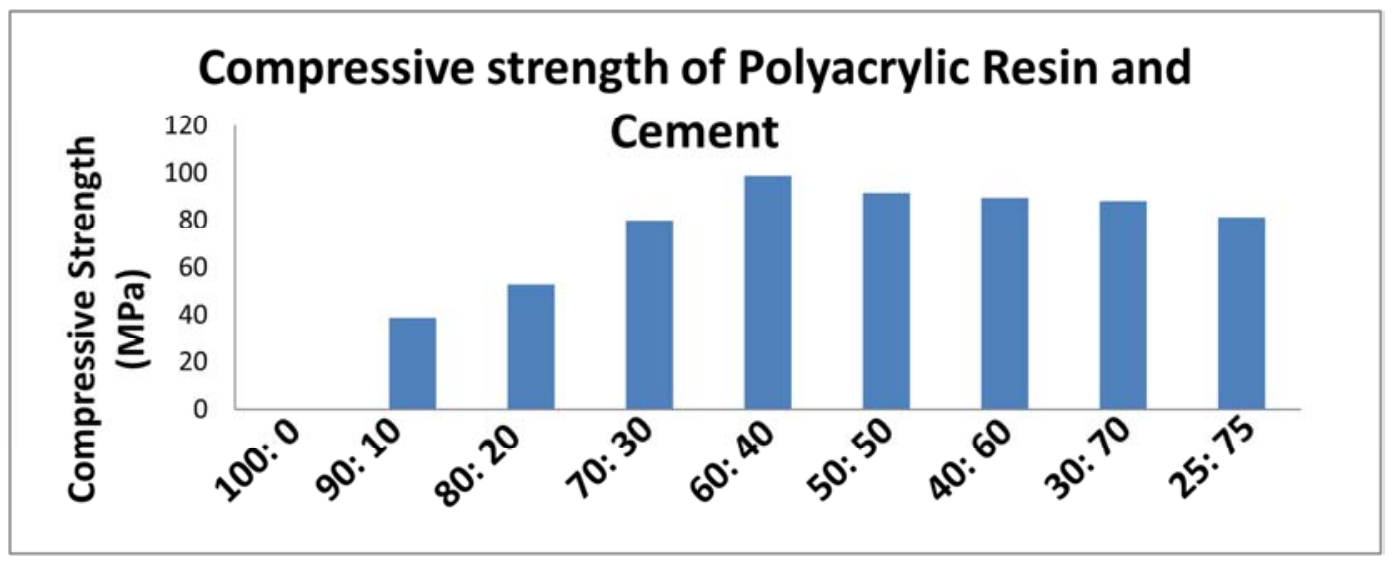

Figure 5. The Compressive strength of Polymeric Cement.

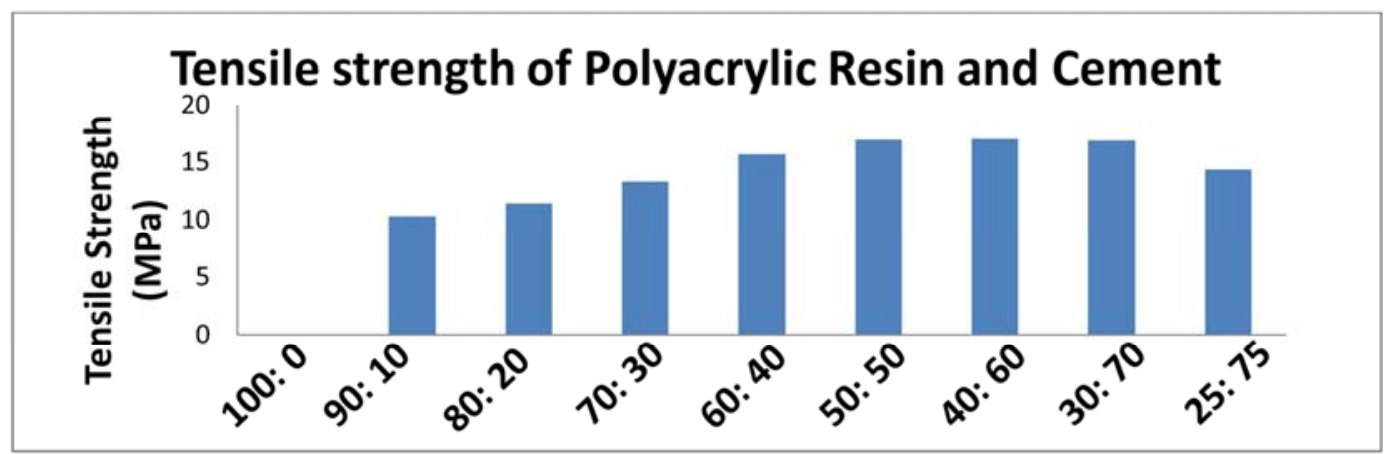

Figure 6. The Tensile strength of Polymeric Cement. 


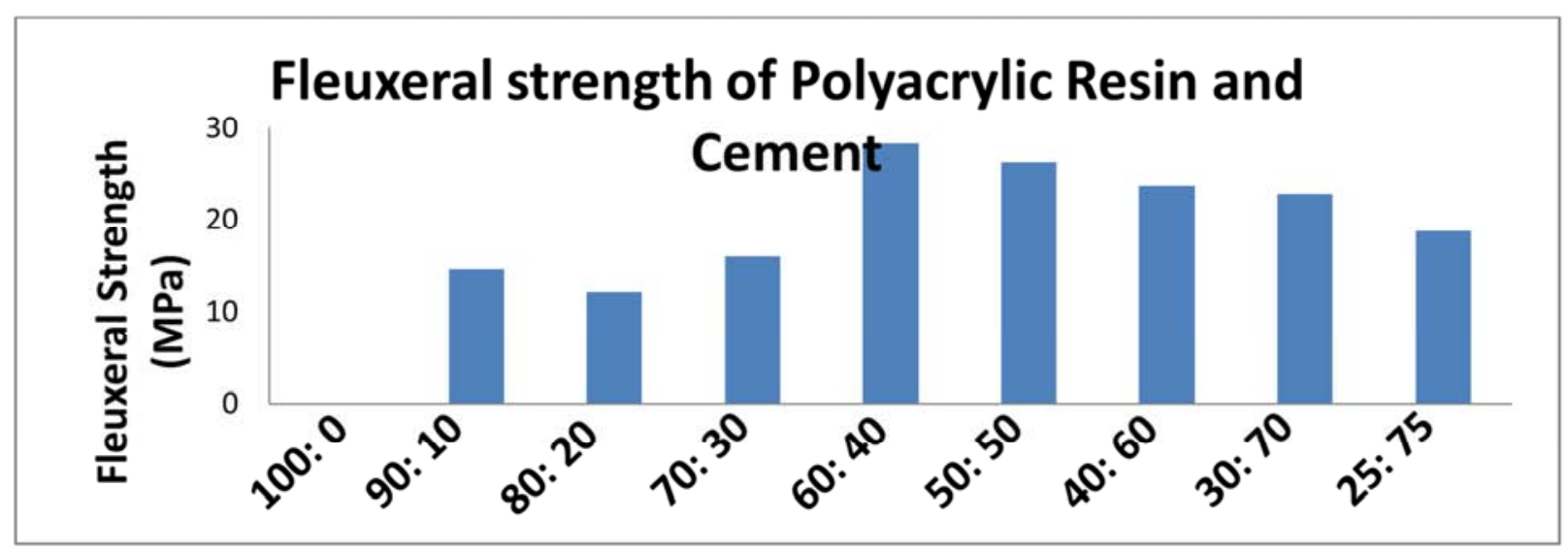

Figure 7. The Fleuxeral strength of Polymeric Cement.

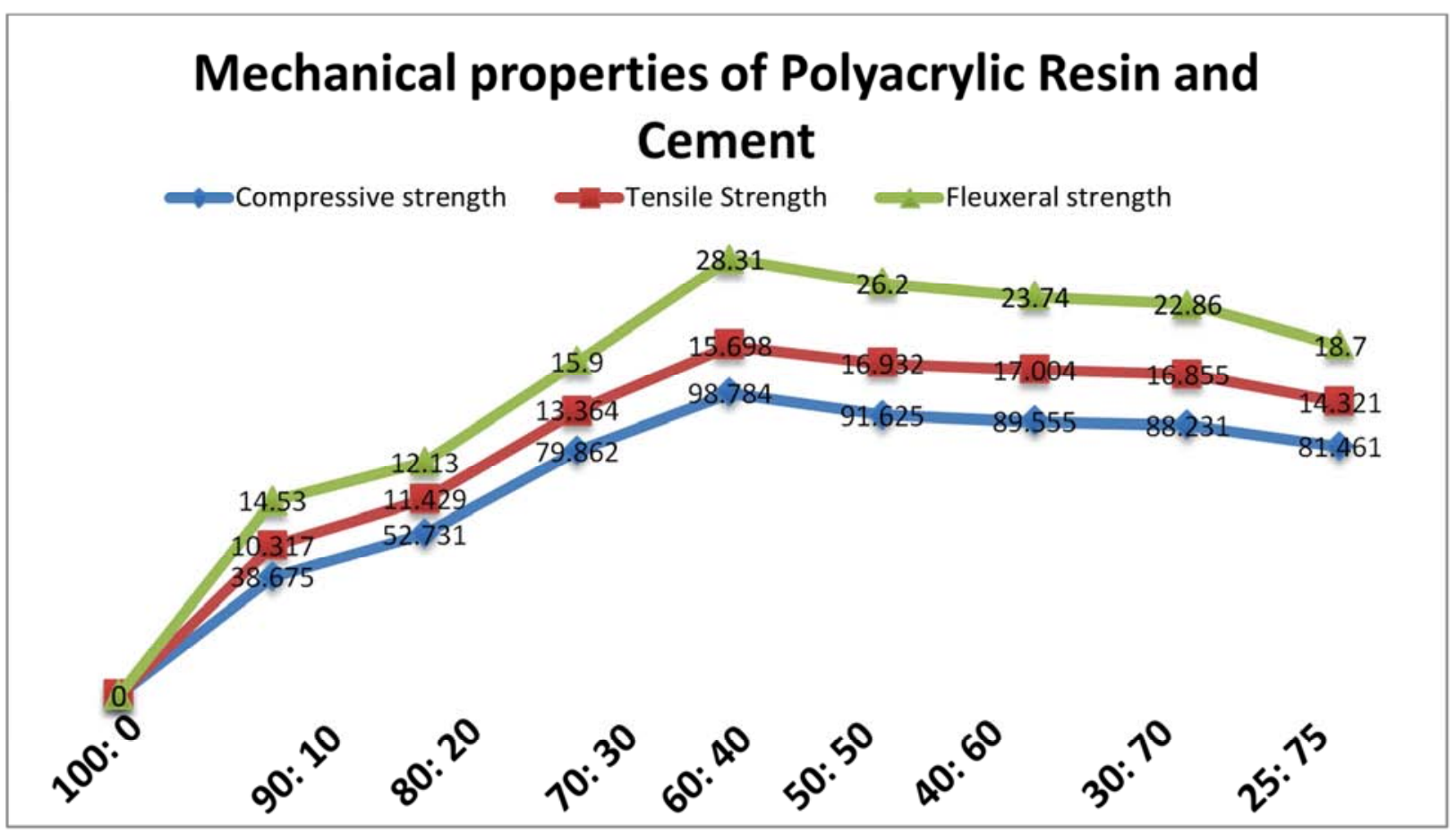

Figure 8. The Mechanical properties of Polymeric Cement.

\subsection{Mechanical Properties of Polymeric Calcium Carbonate}

Table 35. For the mixture of Resin and Calcium carbonate.

\begin{tabular}{llll}
\hline Ratio of mixture of resin and Calcium carbonate & Compressive Strength (MPa) & Tensile Strength (MPa) & Fleuxeral Strength (MPa) \\
\hline 100:0 (standard) & - & - & - \\
$90: 10$ & 33.512 & 8.510 & 12.84 \\
$80: 20$ & 37.261 & 8.901 & 12.91 \\
$70: 30$ & 42.369 & 9.521 & 13.32 \\
$60: 40$ & 44.325 & 9.878 & 14.66 \\
$50: 50$ & 46.227 & 8.154 & 14.89 \\
$40: 60$ & 40.624 & 7.993 & 14.24 \\
$30: 70$ & 39.146 & 7.432 & 13.86 \\
$25: 75$ & 35.232 & 7.210 & 12.90 \\
\hline
\end{tabular}




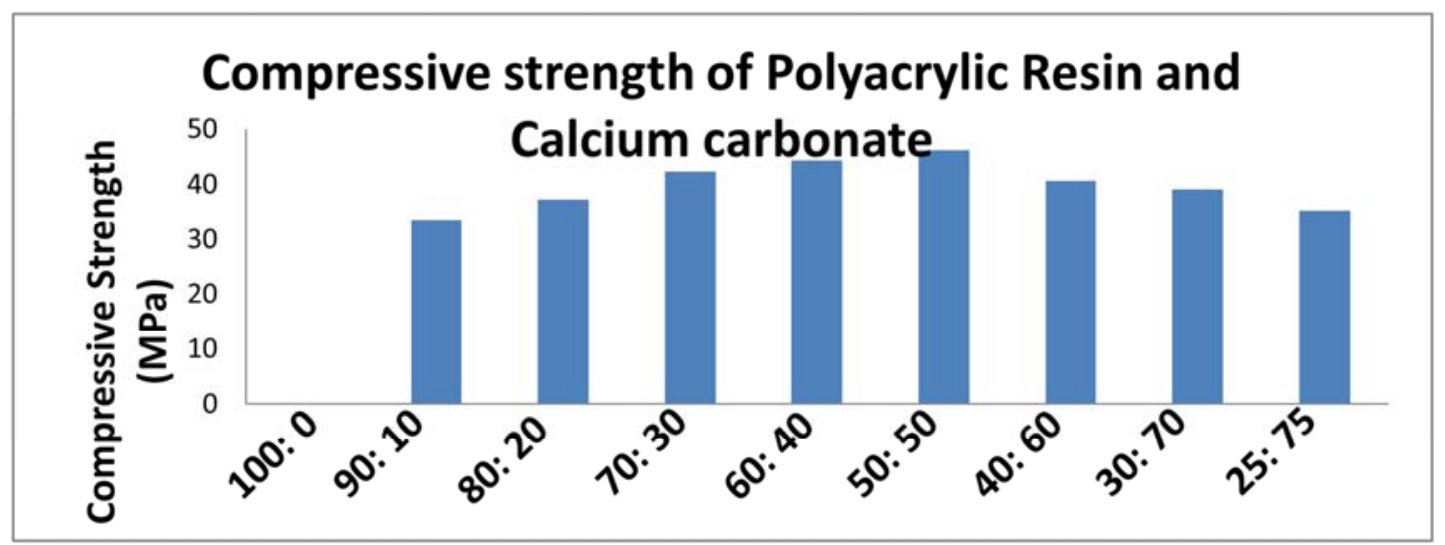

Figure 9. The Compressive strength of Polymeric Calcium carbonate.

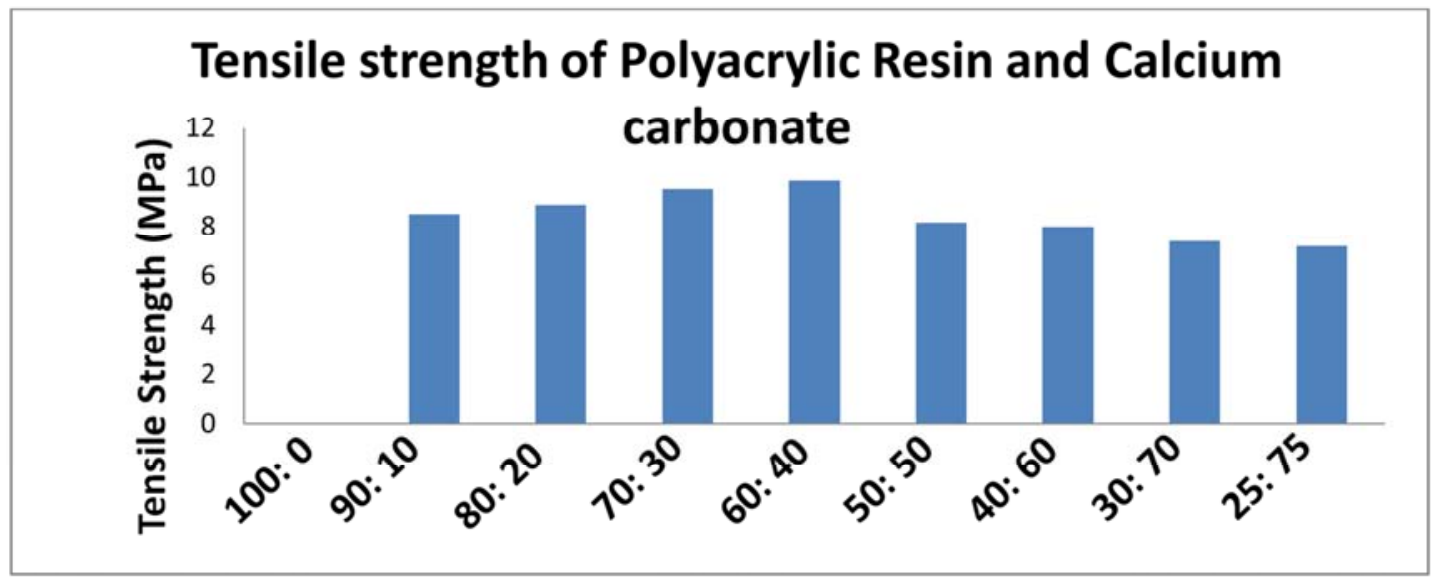

Figure 10. The tensile strength of Polymeric Calcium carbonate.

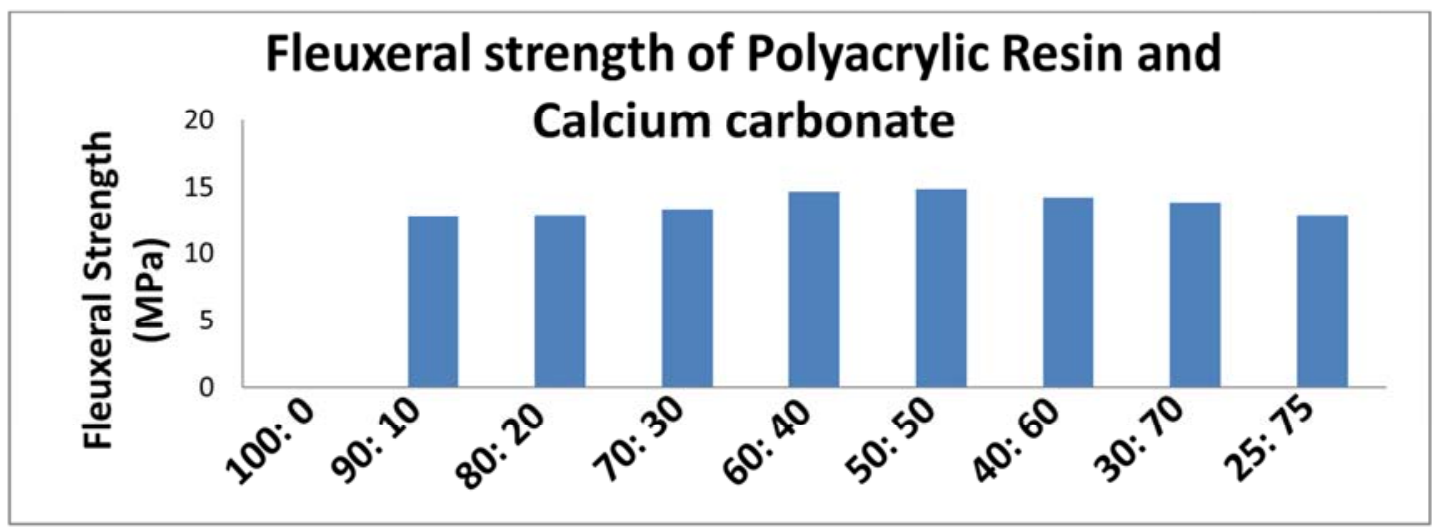

Figure 11. The Fleuxeral strength of Polymeric Calcium carbonate.

\subsection{Mechanical Properties of Polymeric Barite}

Table 36. For the mixture of Resin and Barite.

\begin{tabular}{llll}
\hline Ratio of mixture of resin and Barite & Compressive Strength (MPa) & Tensile Strength (MPa) & Fleuxeral Strength (MPa) \\
\hline 100:0 (standard) & - & - & - \\
$90: 10$ & 38.421 & 14.545 & 9.60 \\
$80: 20$ & 49.465 & 12.458 & 9.95 \\
$70: 30$ & 45.565 & 15.587 & 10.52 \\
$60: 40$ & 48.652 & 16.897 & 10.97 \\
$50: 50$ & 47.456 & 17.879 & 11.55 \\
$40: 60$ & 45.265 & 16.444 & 11.82 \\
$30: 70$ & 45.211 & 16.325 & 12.65 \\
$25: 75$ & 44.953 & 16.588 & 11.74 \\
\hline
\end{tabular}




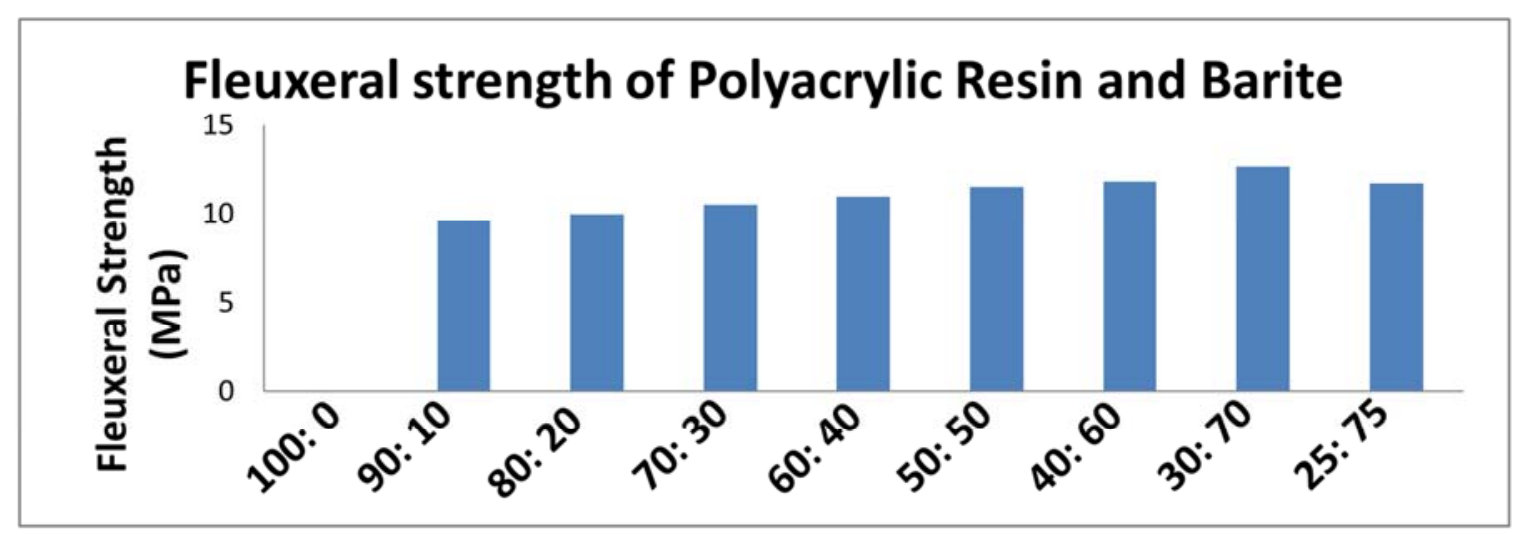

Figure 12. The Fleuxeral strength of Polymeric Barite.

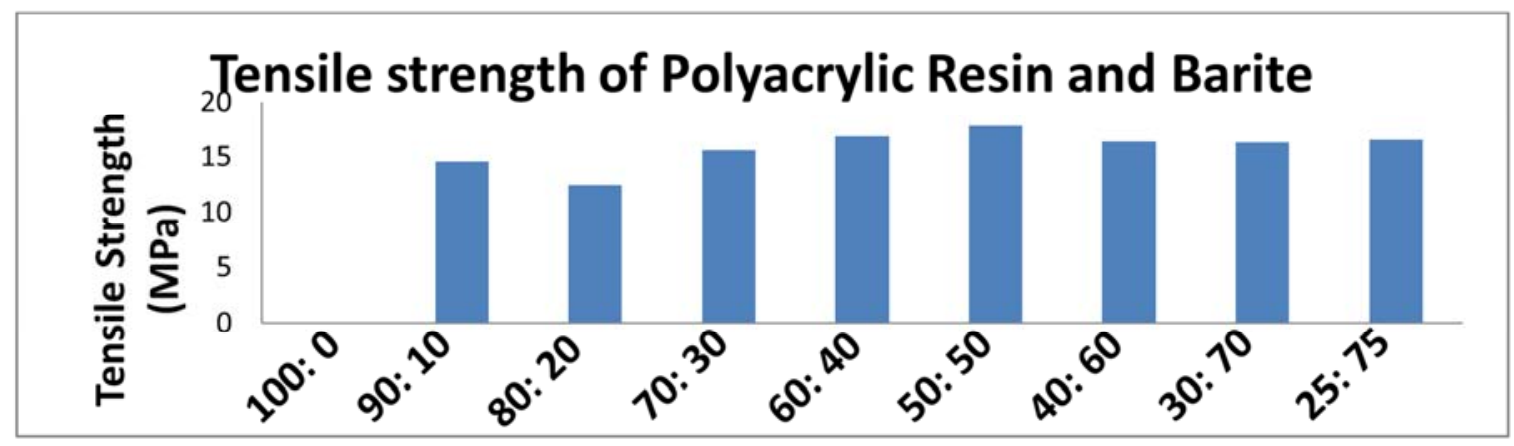

Figure 13. The Tensile strength of Polymeric Barite.

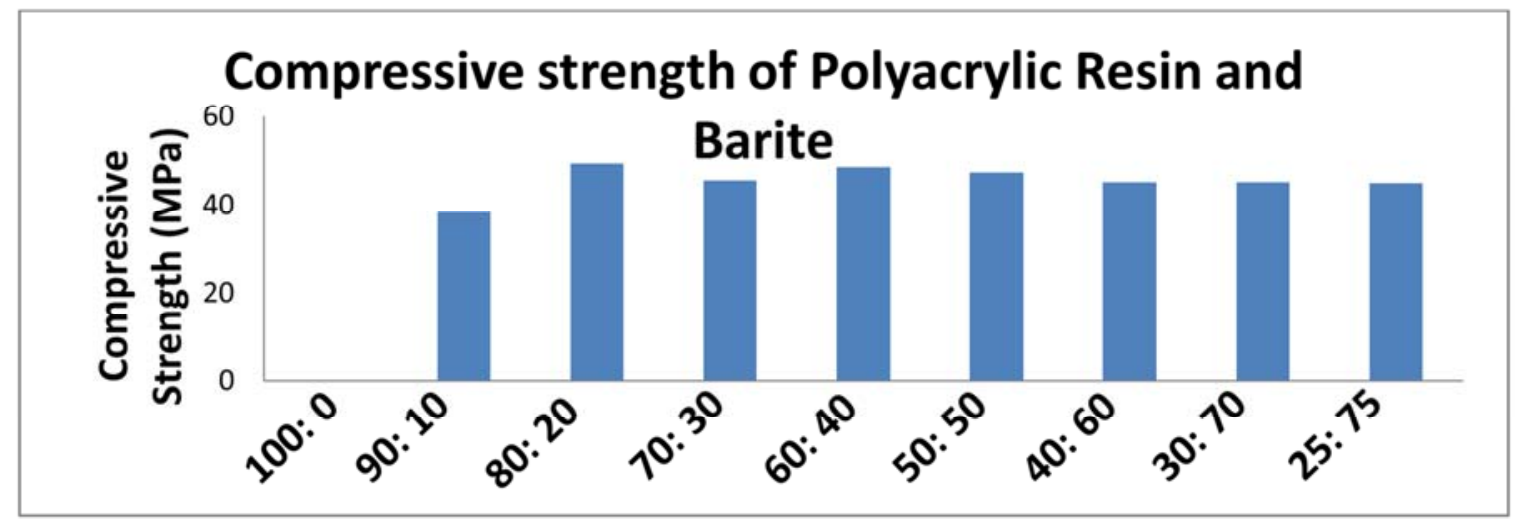

Figure 14. The Compressive strength of Polymeric Barite.

\section{Discussion}

For the ratio 100:0 for the Resin: Cement, Resin: Barite, and Resin: Calcium carbonate, it was observed that curing did not occur. This shows that the addition of the resin without the fillers i.e. Polyacrylic resin would not be cured without the addition of the fillers. According to table 31, the percentage water absorption was within a 0.01 range. The highest value was 0.05 and the lowest, 0.04 . Only two ratios exhibited water absorption of $0.04 \%$ viz; $90: 10$ and 25:75, while the rest exhibited $0.05 \%$ water absorption. According to table 32 , the water absorption ability of the mixture of polyacrylic resin and barite was within the range of 0.02 i.e. from 0.02 to 0.04 . The highest value of water absorption (0.04) was noticed at the $60: 40$ ratio of resin to barite while the lowest value of (0.02) was found the both the 90:10 and 40:60 ratio of resin to barite. According to table 33, the \% Water absorption was within the range of 0.02 i.e. from 0.01 to 0.03 . The highest value of water absorption (0.03) was noticed at the 50:50 ratio of resin to Calcium carbonate while the lowest value of (0.01) was found in the 90:10, 40:60, $30: 70$, and 25:75 ratio of resin to Calcium carbonate. From the experimental result obtained, the ratios 80:20, 70:30, 60:40, 50:50, 40:60, 30:70 for Polyacrylic resin: Cement are the best ratios to obtain optimum water retention. The ratio 60:40, for Polyacrylic resin: Barite is the best ratio to obtain optimum water retention and finally, the ratio 50:50, for Polyacrylic resin: Calcium carbonate is the best ratio to obtain optimum water retention.

The compressive, Tensile and Fleuxeral strength of the 
100:0 of the mixture of the resin and fillers weren't calculated as it didn't cure to solid. The compressive strength of the polymeric cement ranged from 38.675 to 98.784 . It was noticed that the compressive strength increased steadily as the amount of cement was increased and the amount of polymer decreases until it reached a peak, from where it started decreasing. The highest value of compressive strength was reached at the $60: 40$ ratio of Resin: Cement, while the lowest compressive strength was discovered in the 25:75 ratio of Resin: Cement. The tensile strength of the polymeric cement ranged from $10.317 \mathrm{MPa}$ in the $90: 10$ ratios to 17.004MPa in the 40:60 ratio of Resin: Cement. It was noticed that the compressive strength increased steadily as the amount of cement was increased and the amount of polymer decreases until it reached a peak (17.004), from where it started decreasing. The Fleuxeral strength of the polymeric cement ranged from $14.53 \mathrm{MPa}$ in the $90: 10$ ratio to $28.31 \mathrm{MPa}$ in the $60: 40$ ratio of Resin: Cement. It was noticed that the fleuxeral strength increased steadily as the amount of cement was increased and the amount of polymer decreases until it reached a peak, from where it started decreasing. From table 34, the compressive strength of the polymeric cement got to its peak at the 60:40 ratio. This shows that the maximum stress sustained by the Polymeric cement is $98.784 \mathrm{MPa}$ at the $60: 40$ ratio. The tensile strength of the polymeric cement got to its peak at the 40:60 ratio, while the fleuxeral strength of the polymeric cement got to its peak at the 60:40 ratio. From these results, it shows that the ratio of the highest strength of the polymeric cement is the 60:40 ratio of Resin: Cement.

The compressive strength of the polymeric Calcium carbonate ranged from 33.512 to 46.227 . It was noticed that the compressive strength increased steadily as the amount of Calcium carbonate was increased and the amount of polymer decreases until it reached a peak, from where it started decreasing. The highest value of compressive strength was reached at the 50:50 ratio of Resin: Calcium carbonate, while the lowest compressive strength was discovered in the 90:10 ratio of Resin: Calcium carbonate. The tensile strength of the polymeric Calcium carbonate ranged from $7.210 \mathrm{MPa}$ in the $25: 75$ ratios to $9.878 \mathrm{MPa}$ in the $60: 40$ ratio of Resin: Calcium carbonate. It was noticed that the compressive strength increased steadily as the amount of Calcium carbonate was increased and the amount of polymer decreases until it reached a peak (9.878), from where it started decreasing. The Fleuxeral strength of the polymeric Calcium carbonate ranged from $12.84 \mathrm{MPa}$ in the $90: 10$ ratio to $14.89 \mathrm{MPa}$ in the $50: 50$ ratio of Resin: Calcium carbonate. It was noticed that the fleuxeral strength increased steadily as the amount of Calcium carbonate was increased and the amount of polymer decreases until it reached a peak, from where it started decreasing. From table 35, the compressive strength of the polymeric Calcium carbonate got to its peak at the 50:50 ratio. This shows that the maximum stress sustained by the Polymeric Calcium carbonate is $46.227 \mathrm{MPa}$ at the 50:50 ratio. The tensile strength of the polymeric Calcium carbonate got to its peak at the 40:60 ratio, while the fleuxeral strength of the polymeric Calcium carbonate got to its peak at the 50:50 ratio.

The compressive strength of the polymeric Barite ranged from $38.421 \mathrm{MPa}$ to $48.652 \mathrm{MPa}$. From table 36 , it was noticed that the compressive strength increased steadily as the amount of Barite was increased and the amount of polymer decreases until it reached a peak, from where it started decreasing. The highest value of compressive strength was reached at the 60:40 ratio of Resin: Barite, while the lowest compressive strength was discovered in the 90:10 ratio of Resin: Barite. The tensile strength of the polymeric Barite ranged from $12.458 \mathrm{MPa}$ in the $80: 20$ ratios to $17.879 \mathrm{MPa}$ in the $50: 50$ ratio of Resin: Barite. It was noticed that the compressive strength increased steadily as the amount of Barite was increased and the amount of polymer decreases until it reached a peak (17.879), from where it started decreasing. The Fleuxeral strength of the polymeric barite ranged from $9.60 \mathrm{MPa}$ in the $90: 10$ ratio to $12.65 \mathrm{MPa}$ in the 30:70 ratio of Resin: barite. It was noticed that the Fleuxeral strength increased steadily as the amount of Barite was increased and the amount of polymer decreases until it reached a peak, from where it started decreasing. From table 36 , the compressive strength of the polymeric barite got to its peak at the 60:40 ratio. This shows that the maximum stress sustained by the Polymeric Barite is $48.652 \mathrm{MPa}$ at the $60: 40$ ratio. The tensile strength of the polymeric Barite got to its peak at the 50:50 ratio, while the fleuxeral strength of the polymeric Barite got to its peak at the 30:70 ratio.

\section{Conclusion}

From the research conducted on the Water absorption and Mechanical properties of the mixture of Cement, Barite, Calcium carbonate and Polyacrylic resin, it was discovered that the resin was unable to cure without the addition of any filler. This made it impossible to determine its Mechanical and Water absorption property. The results of this work confirmed that the ratios 80:20, 70:30, 60:40, 50:50, 40:60, 30:70 for Polyacrylic resin: Cement are the best ratios to obtain optimum water retention. The ratio 60:40, for Polyacrylic resin: Barite is the best ratio to obtain optimum water retention and finally, the ratio 50:50, for Polyacrylic resin: Calcium carbonate is the best ratio to obtain optimum water retention. The results of this work also confirmed that from the compressive strength graphs; the optimum compressive strength of the polymeric cement, Calcium carbonate and Barite were the ratios 60:40, 50:50, and 80:20 respectively. It was observed during the course of this work that as the amount of Polyacrylic resin was reduced and the amount of filler was increased, the strength of the polymeric material was observed to increase until a peak was gotten and then it started decreasing.

It can therefore be deduced from this research that the addition of Polyacrylic resins to the materials; Portland cement, Calcium carbonate and Barite would increase its water retention capacity as well as its mechanical properties. Polyacrylic resin is recommended as a reinforcer to materials. 


\section{References}

[1] Al-Eshaikh, M. A., and Qureshi, M. I. Probing of dielectric properties of high density polyethylene/calcium carbonate $\left(\mathrm{HDPE} / \mathrm{CaCO}_{3}\right)$ nano- microcomposite. International Journal of Physical Sciences, 8 (4): 167-174.

[2] Annan, E., Agyei-Tuffour, B., Damoah, L. N. W., Konadu, D. S., and Mensah, B. (2012). Mechanical properties of bauxite residue-clay bricks. ARPN Journal of Engineering and Applied Sciences, 7 (12): 1587-1594.

[3] Baran, B. H. (2010). Comparison of Mechanical Properties for Polymer Concrete with Different Types of Filler. Journal of Materials in Civil Engineering, 22 (1): 696-701.

[4] Barbuta, M., Serbanoiu, A. A., Teodorescu, R., Rosca, B., Mitroi, R., and Bejan, G. (2017). Characterization of polymer concrete with natural fibres. IOP Conference Series: Materials Science and Engineering, 246 (1): 1-5.

[5] Mignon, A., Snoeck, D., Dubruel, P., Vlierberghe, S., and Belie, N. (2017). Crack mitigation in concrete: Superabsorbent polymers as key to success. MDPI Journal, 10 (273); 1-25.

[6] Craft, R. S. (2004). Properties of Polymer Concrete using Fly Ash. Journal of Material in Civil Engineering, 16 (1): 15-19.

[7] Golestaneh, M. (2010). Evaluation of Mechanical Strength of concrete polymer. World Applied Sciences Journal, 9 (2): 216220.

[8] Ismail, M. Muhammad, B., Yatim, J. M., Noruzman, A. H., and Soon, W. Y. (2011). Behaviour of concrete with polymer additive at fresh and hardened states. Journal of Procedia Engineering, 14 (1): 2230-2237.

[9] Kazmierczac, G. M. (2004). Study of the Modulus of Elasticity of polymer concrete compounds and comparative assessment of polymer concrete and Portland cement concrete. Cement and Concrete Research, 34 (1): 2091-2095.

[10] Lukowski, P. (2016). Polymer-Cement Composites Containing Waste Perlite Powder. Materials Journal (MDPI), 9 (839): 111 .

[11] Building Research Institute, (2015). Material Testing. [Online] Available at: http://www.buildingresearch.com.np/services/mt/mt1.php [Accessed 27th June 2018].

[12] Mohammed, M. H. (2012). Optimization of Concrete by Minimizing Void Volume in Aggregate Mixture System. Journal of Advanced Science and Engineering Research, 2 (3): 208-222.

[13] System i Technologie, (2009). Modern Construction Polymer Concrete. [Online] Available at: http://www.sytec.pl/en/polimerobeton-en.php [Accessed 27th June 2018].

[14] Mingli, C., Xing, M., Kaiyu, H., Li, L., and Shirley, S. (2019). Effect of Macro-, Micro- and Nano-Calcium Carbonate on properties of Cementitious Composites - A review. MPDI Journal of Materials, 12 (781); 1-20.

[15] Francisco, C., Laura, M., Julia, I. R., Teresa, R. (2014). Mechanical and Physical properties of Polyester Polymer Concrete Using Recycled Aggregates from Concrete Sleepers. The Scientific World Journal Volume, 1 (1); 1-10. 